\title{
Evaluation of Gum Katira as a Model Sustained Release Adjuvant in the Preparation of Etodolac Loaded Microsphere
}

\author{
Biswajit Ruhidas, Debjyoti Naskar, Saswata Banerjee, Saumen Karan and Tapan Kumar Chatterjee* \\ Department of Pharmaceutical Technology, Jadavpur University, Kolkata-32, India.
}

\begin{abstract}
Aims: The aim of present study was to evaluate Gum Katira obtained from the plant Cochlospermum religiosum (Family Cochlospermaceae) as a matrix forming pharmaceutical excipient for a novel drug delivery system. Materials and Methods: Gum Katira was used for the drug release retarding material in microsphere formulation using Etodolac as a model drug. Etodolac was found to be compatible with the matrix material Gum Katira by conducting the various physiochemical and instrumental analysis. Result: Etodolac loaded Gum Katira microsphere (ELGKM) was compared with Etodolac loaded sodium alginate microsphere (ELSAM) and blank microsphere (without gum matrix), which subsequently revealed that the drug release rate of ELGKM was better for sustained and controlled release. Conclusion: In our experiment, it was found that the drug release mechanism best fitted in Korsmeyers Peppas model on comparing the correlation coefficient values of different mathematical models. The result of this study indicates that ELGKM (1\% w/v Gum Katira) would be desired formulations in delivering the drug with controlled and sustained release pattern.
\end{abstract}

Key words: Etodolac, Gum Katira, Gum Matrix, Rheogram, Sustained release.

\section{INTRODUCTION}

Novel drug delivery system has reached its pinnacle in last few years. Sustained drug delivery system is advantageous with its prolonged drug release mechanism which is desirable from the therapeutic point of view, for the treatment of chronic pain syndromes like nocturnal asthma, angina pectoris and rheumatoid arthritis. ${ }^{1}$

Sustained drug delivery systems maintain the drug level at the therapeutic optimum which is needed in the blood in a numbers of pathological conditions. Therefore, the preparation of controlled and sustained drug delivery system is one of the most important tasks of pharmaceutical technologist. ${ }^{2}$ Research has been performed on prodrug, $\mathrm{pH}$, time dependent and polysaccharide based drug delivery system leading to unsatisfactory results, so further investigation on natural gum based microsphere was initiated..$^{3-5}$ Multiunit sustained release formulation like microspheres pass through the gut as if a solution avoiding the vagaries of gastric emptying and different transient rates and thereby, release drugs more uniformly, and spread over a large area of absorbing mucosa decreasing dose dumping and preventing exposure to high drug concentration. ${ }^{6,7}$

Drug release retarding polymers are the key performers in designing a dosage form for oral sustained release formulation. ${ }^{8}$ The natural polysaccharides (excipients of natural origin) are the attractive alternative product because of their reliability, biocompatibility, biodegradability, sustainability, low toxicity and low cost compared to synthetic product. ${ }^{9}$ Natural Polysaccharide such as guar gum, xanthan gum, and locast bean gum has been investigated for their use in Novel drug delivery system. ${ }^{10}$ They remain undigested in stomach but get degraded by different anaerobic microflora in the intes-
Submission Date : 02-06-2015 Revision Date : :24-07-2015 Accepted Date : :19-07-2015

DOI: 10.5530/ijper.50.1.19 Correspondence Address Dr. Tapan Kumar Chatterjee

Department of PharmaceuticalTechnology, Jadavpur University, Kolkata-32, India.

Email:crctkc@gmail.com

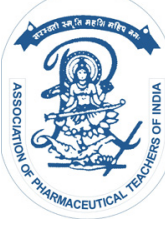

www.ijper.org 
tine. ${ }^{11}$ Gum Katira was selected as the matrix forming material because of its well-established biocompatibility, non toxic and safe material for the use in food and pharmaceutical industries. ${ }^{12}$ Gum Katira is a novel heteropolysaccharide isolated from Cochlospermum religiosum and consists of D-galactose, D-galactouronic acid and L-rhamnose in a molecular ratio 2:1:3 respectively together with traces of a ketohexose. ${ }^{13}$ This gum is pale, semi transparent and swells to form a pasty transparent mass with water. ${ }^{14}$ Different physiochemical properties of Gum Katira such as solubility, percentage of swelling, and rheogram etc have been studied. Increment in shear stress on increasing shear rate confirmed the pseudoplastic nature that may be a suitable characteristic for the controlled and sustained release drug delivery formulations. ${ }^{15}$ The instrumental techniques like SEM, DSC, X ray diffraction, FT-IR, etc were performed to establish that Gum Katira has no interactions with the ingredients used in the microsphere formulation containing a polymeric substance as a carrier and a coating material.

Etodolac, a non steroidal anti-inflammatory drug, used in the treatment of various acute and chronic pain syndromes like osteoarthritis, rheumatoid arthritis and other types of joint pain. ${ }^{16}$ Etodolac is taken as a model drug because of its short half life, low water solubility and ready absorbility throughout the gastrointestinal tract. ${ }^{17,18}$ However, its immediate release formulations shows severe side effects like gastric irritation, bleeding, ulceration and eventually wall perforation especially in chronic dosing led to the formulation of microsphere, a sustained release dosage form. ${ }^{19}$

Eudragit which is one of the most thoroughly investigated synthetic polymers for sustained drug delivery system is being used as a coating material in this formulation. ${ }^{20,21}$ Eudragit RS 100 and RL 100 are taken due to their biocompatibility, good stability, easy fabrication and insolubility in gastric juice. ${ }^{22-25}$

In contrary to conventional dosage forms like tablets and capsules, formulations which are present in the market with better effectiveness also have higher side effects on gastrointestinal system ${ }^{26}$ and cardiovascular system $^{27}$ on administration of more than $400 \mathrm{mg}$ dose. The use of microsphere for drug delivery is not limited to any specific illness, rather they can be widely applied in many situations where continuous or controlled drug administration is essential.

\section{MATERIALS AND METHODS}

\section{Materials}

Crude Gum Katira was collected from the Seoni district of Madhya Pradesh. Etodolac was obtained as a gift sam- ple from Fleming Laboratories Limited Medak district, Andhra Pradesh, India. Eudragit RS100 and Eudragit RL100 were purchased from the Yarro Chem Products Mumbai (India), Dichloromethane, Tween 80 and Span 20 (Merck, India), and all other reagents were of analytical grade obtained commercially and used as received.

\section{Methods}

\section{Collection and Purification of Gum Katira}

Crude gum was collected as dried exudates from the branches of the fibrous exudates of plant Chochlospermum religiosum (Hindi: Galgal) in the month of December from Seoni district of Madhya Pradesh, India. For purification larger dust particles were removed manually and air dried well. Dried gum exudates was then kept overnight in water. Gum was allowed to swell fully to form ribbon shaped transparent mass. Again larger visible foreign particles were removed carefully. The transparent mass was stirred vigorously using mechanical stirrer for 3 hrs. The remaining minute dust particles were then removed manually. The finally obtained white material was then oven dried at $70^{\circ} \mathrm{C}$ for 2 days. Particle size of oven dried material was reduced as much as possible by using mortar and pestle and finally kept in air dried container for optimum storage.

\section{Solubility}

The solubility of Gum Katira was evaluated randomly in water, acetone, chloroform, ethanol and most of the other organic solvents. As a result, the gummy exudates were found to be slightly soluble in water and insoluble in most of organic solvents used like Ethanol, chloroform and acetone.

\section{Particle size and Melting Point determination}

The particle size of the Gum Katira was determined by the help of Zetasizer (ASU), Model No. Nano ZS 90, Malvern, UK. The melting point of the Gum Katira was determined by digital melting point apparatus (model VMP-D, Veego, Mumbai). For this the gum powder was taken in the capillary tube of the apparatus. As the temperature of the apparatus rises, solid starts transforming into liquid but in case of natural polysaccharides the transition from solid to liquid is followed by charring during the melting process. Gum Katira powder starts charring at $80-90^{\circ} \mathrm{C}$.

\section{Determination of Moisture content}

Moisture content of Gum Katira was determined by Carl Fischer titration method. The gum powder was dispersed in methanol, stirred well for 5 minutes to remove the water and titrated with standardized Karl Fischer 
reagent till the end point. Moisture content was calculated using the following formula.

Moisture content $(\%)=V_{1} \times W_{e} / S_{w \times} 100$

Where $\mathrm{V}_{1}$ is the volume of Karl Fischer reagent used, $\mathrm{W}_{\mathrm{e}}$ is the water equivalent and $\mathrm{S}_{\mathrm{w}}$ is the weight of sample. Water equivalent is $5.2 ; 15 \mathrm{ml}$ of reagent is equal to $75 \mathrm{mg}$ of water.

\section{Microbial Load Study}

Microbial load of the Gum Katira was observed on fresh sample and 10 months older sample. The sample was analyzed for total aerobic microbial count and fungal count by pour plate method. $1 \mu \mathrm{m} / \mathrm{ml}$ of gum dispersion was incubated in soybean casein digest sugar medium, poured inpetridish and allowed to solidify. The plate was left for $1 \mathrm{hr}$ at $10^{\circ} \mathrm{C}$ and incubated at $37^{\circ} \mathrm{C}$ for a day. The total no of colonies formed were counted. Total fungal count was done using potato dextrose agar medium. The plates are incubated at room temperature for $72 \mathrm{hrs}$.

\section{Swelling characteristic of Gum Katira}

Rate of swelling/ hydration of ELGKM and ELSAM in same concentration were evaluated to study the mechanism of drug release from the hydrated gum and extent of water uptake by the gum. Swelling capacity was evaluated in terms of weight gain by the microsphere. Accurately weighed microspheres were placed on petridishes having the dissolution media $(\mathrm{pH} 1.2$ $\mathrm{HCl}$ media for $2 \mathrm{hrs}$ and $\mathrm{pH} 6.8$ phosphate buffers for $10 \mathrm{hrs}$ ). Swollen Microspheres were withdrawn periodically from the medium and weighed in an electronic balance (Model No. D455001482, Shimadzu corp, Japan) after removing the excess surface water using tissue paper. The same process was repeated for $12 \mathrm{hrs}$ and gain in weighed was recorded. Percentage swelling was calculated according to the below mentioned formula: $\%$ swelling of Gum $=\left[\left(S_{t}-S_{\theta}\right) / S_{\theta}\right] \times 100$

Where $S_{0}$ is the initial weight of microspheres and $S_{t}$ is the weight of hydrated Microspheres.

The rate of swelling of ELGKM and ELSAM in $\mathrm{pH}-1.2 \mathrm{HCl}$ media and $\mathrm{pH}-6.8$ phosphate media were determined using the following relationship.

Rate of Swelling = Slope of [\% Swelling of Gum vs. VTime] curve.

\section{Rheological Study}

The Rheological properties were determined by using Rheometer (Anton Paar, and Model No. MRC 102, Austria). For this Gum Katira (1\%w/v, 2\%w/v) dispersion and sodium alginate $(1 \% \mathrm{w} / \mathrm{v})$ solution were prepared with distilled water and allowed to stand for $24 \mathrm{hrs}$. Then the gum solution was analyzed at different shear stress vs shear rate and shear rate vs viscosity at different time intervals at $12^{\text {th }} \mathrm{hr}$ and $24^{\text {th }} \mathrm{hr}$ respectively.

\section{Toxicity Study}

The acute toxicity study was carried out in adult Swiss albino mice (20-25 g) by "fixed dose" method of OECD (Organization for Economic Cooperation and development) guideline no.423 and 407 respectively. The subacute toxicity study was conducted on male wistar rat (150-200 g). The solution of gum katira at dose of 100,200 and $400 \mathrm{mg} / \mathrm{kg}$ body weight was administered orally to three groups of six rats respectively in every 24 hrs for 30 days and a control received vehicle of same volume. The toxic manifestation i.e. body weight, mortility and behavioral changes were regularly monitored. After thirty days all the surviving animals were fastened overnight and anaesthetized with ether and the heparinized blood samples were collected for determination of haematological parameters followed by sacrificing the animals for the collection of internal organs kidney and liver. The collected organs were then preserved in 10\% formaldehyde solution for histopathological examination. The research was conducted in accordance with the ethical rules on animal experimentation approved by Ethical committee, Department of Pharmaceutical Technology, Jadavpur University (Approval No: 147/1999/CPCSEA).

\section{Determination of $\lambda_{\text {max }}$ of Drug}

A solution of Etodolac having a conc. $1 \mu \mathrm{g} / \mathrm{ml}$ was prepared in acid (pH-1.2) and phosphate buffer ( $\mathrm{pH}-6.8$ ) separately. UV spectrum was taken using double beam spectrophotometer (MULTISKAN GO, Thermo Scientific). The solution was scanned in the range of 200$400 \mathrm{~nm}$. The wavelength of maximum absorption of Etodolac was found to be $224 \mathrm{~nm}$ in both the cases.

\section{Determination of Melting Point of Drug}

The melting point of Etodolac was determined by open capillary method using melting point apparatus VEEGO, (Model No.VMP-DS). The melting point of Etodolac was found to be $150.5-151.5^{\circ} \mathrm{C}$.

\section{Preparation of Microsphere}

Etodolac microspheres were prepared by double-emulsion solvent evaporation technique. Matrix material Gum Katira (50 mg) was mixed with distilled water to form a homogeneous mixture in magnetic stirrer for 30 minutes with a constant temperature of $40-45^{\circ} \mathrm{C}$. Etodolac $(50 \mathrm{mg})$ was added to the homogeneous mixture and stirring was continued for another 30 minutes. This mixture was then dispersed in a solution of Eudragit RS and RL 100, Dichloromethane, Acryflow and span 20 through a 20 guage syringe. The above mixture was homogenized well for 5 minutes using homogenizer to form W1/O emulsion. Another solution 
of distilled $(100 \mathrm{ml})$ water containing Tween 80 was subjected to mechanical stirring $(700-800 \mathrm{rpm})$ and to it the previously prepared $\mathrm{W}_{1} / \mathrm{O}$ emulsion was added drop wise using a 16 guage syringe to form $\mathrm{W} 1 / \mathrm{O} / \mathrm{W} 2$ emulsion with a continues stirring for 1-1.5 hrs. The resultant microspheres formed were washed with distilled water followed by air drying for $24 \mathrm{hrs}$ and final storage in desiccators for further use.

\section{Percentage of Yield and Encapsulation efficiency of the Microspheres}

The percentage of yield is calculated to know the maximum practical yield of the products. Etodolac loaded microspheres were prepared having production yield near about $80-95 \%$. The percentage yield of prepared formulation was determined by using the formula:

Percentage Yield $=[$ Practical Yield/Theoretical Yield] X 100

Crushed and Powder $30 \mathrm{mg}$ of Etodolac loaded Microspheres were dissolved in $5 \mathrm{ml}$ of Dichloromethane (DCM). This solution was stirred for $1 \mathrm{hr}$ using magnetic stirrer for the complete dissolution of Polymer in DCM. $45 \mathrm{ml}$ of phosphate buffer $\mathrm{pH}-6.8$ was added to this solution. This solution was magnetically stirred for $1 \mathrm{hr}$ at $40-45^{\circ} \mathrm{C}$ and then filtered. About $4 \mathrm{ml}$ of filtered solution was taken and added to $21 \mathrm{ml}$ of fresh phosphate buffer to make $25 \mathrm{ml}$ of aliquot. The absorbance of the final solution was measured at $224 \mathrm{~nm}$ using double beam UV-Visible spectrophotometer against phosphate buffer pH-6.8 as blank and calculation was done for the percentage of drug loading in sample. Drug loading efficiency was found to range between 45-60\%. Efficiency of drug loading for each batch was calculated in terms of percentage of drug loading (PDL) as per the following formula:

$P D L=[$ Practical drug content $/$ Theoretical drug content $]$ X 100

\section{Scanning Electron Microscope Analysis}

Scanning Electron Microscope (SEM) studies were carried out by using JEOL MAKE (UK), (MODEL-JSM6360). Microspheres were mounted on conducting stubs using double sided adhesive tape and vacuum coated with gold palladium film using a sputter coater (Edward S-150, UK). Images were taken using $17 \mathrm{kV}$ electron beam intensity in a scanning electron micro-scope to examine the surface morphology of the samples.

\section{FTIR Spectroscopic Study}

Fourier Transform Infra Red (FTIR) spectroscopy was performed on IR- Prestige-21, Shimadzu make, Japan. FTIR study was carried on Etodolac, Gum Katira and Microsphere shows their characteristic peaks in the region from $400-4000 \mathrm{~cm}^{-1}$.

\section{Differential Scanning Calorimetric Analysis}

Differential Scanning Calorimetric (DSC) was performed to study the changing thermal behavior of the drug, polymer and gum during formulation. Thermograms are evaluated to detect the melting point and change in enthalpy of melting of the samples. Thermograms of Etodolac, Gum Katira and formulation were prepared by Model No. Pyris Diamond TG/DTA, Perkin Elmer (SINGAPORE), Nitrogen Atmosphere $(150 \mathrm{ml} / \mathrm{min})$. Platinum crucible was used with alpha alumina powder as reference to study the changing thermal behavior of the drug, polymer and the gum.

\section{XRD Study}

X-ray diffractometry of Gum Katira, Etodolac and Etodolac loaded Microsphere were performed by a X-Ray Diffractometer using Model no. Ultima-III, Regaku make (Japan), Cu target slide $10 \mathrm{~mm}$. to observe the physical state of Etodolac in the Microsphere.

\section{In vitro Drug Release Study}

In vitro drug release studies were performed by using USP II dissolution test apparatus (Model TDP-06P, Electro Lab, Mumbai, India). Dissolution studies of all microspheres were carried out in $0.1 \mathrm{~N} \mathrm{HCl}, \mathrm{pH}-1.2$ acidic media for an initial 2 hrs followed by USP phosphate buffer, pH 6.8 for the rest of the period at 75 $\mathrm{rpm}$ maintained at a temperature of $37^{\circ} \mathrm{C} \pm 0.5^{\circ} \mathrm{C}$. Aliquots were withdrawn at specific time interval and replenished immediately with the same volume of fresh solution. The drug release was analyzed by UV-Visible Spectrophotometer (MULTISKAN GO, Thermo Scientific) at $224 \mathrm{~nm}$. All release studies were triplicated. The drug release behavior of ELGKM was compared with ELSAM and blank Microsphere.

\section{Statistical analysis}

The data obtained were analyzed statistically using oneway ANOVA and t-test by using Graph Pad prism 5.

\section{RESULTS AND DISCUSSIONS}

\section{Physiochemical Evaluation of Gum Katira}

\section{Solubility}

Gum Katira is slightly soluble in water and form reddish brown color dispersion. It is practically insoluble in ethanol, acetone, chloroform and most of the organic solvent. The gum forms a viscous colloidal dispersion with warm water. This type of matrix forming solu- 


\begin{tabular}{|c|c|c|c|c|}
\hline Parameters & Control & $100 \mathrm{mg} / \mathrm{kg}$ & $200 \mathrm{mg} / \mathrm{kg}$ & $400 \mathrm{mg} / \mathrm{kg}$ \\
\hline Haemoglobin (gm $\%)$ & $14.41 \pm 0.043$ & $14.40 \pm 0.034$ & $14.45 \pm 0.036$ & $14.38 \pm 0.021$ \\
\hline RBC $\left(10^{6} / \mu \mathrm{l}\right)$ & $8.83 \pm 0.067$ & $8.92 \pm 0.084$ & $9.01 \pm 0.101$ & $8.95 \pm 0.076$ \\
\hline WBC $\left(10^{3} / \mu \mathrm{I}\right)$ & $13.97 \pm 0.068$ & $14.05 \pm 0.065$ & $13.93 \pm 0.093$ & $14.16 \pm 0.073$ \\
\hline Neutrophil $\left(10^{3} / \mu \mathrm{l}\right)$ & $21.83 \pm 0.792$ & $22.83 \pm 0.703$ & $21.83 \pm 0.703$ & $22.50 \pm 0.428$ \\
\hline Monocyte $\left(10^{3} / \mu \mathrm{l}\right)$ & $2.26 \pm 0.071$ & $2.21 \pm 0.060$ & $2.30 \pm 0.044$ & $2.35 \pm 0.042$ \\
\hline Lymphocyte $\left(10^{3} / \mu \mathrm{l}\right)$ & $73.67 \pm 0.494$ & $73.50 \pm 0.428$ & $73.83 \pm 0.477$ & $72.50 \pm 0.619$ \\
\hline Eosinophil $\left(10^{3} / \mu \mathrm{l}\right)$ & $2.20 \pm 0.077$ & $2.11 \pm 0.079$ & $2.35 \pm 0.076$ & $2.41 \pm 0.047$ \\
\hline Platelets $\left(10^{3} / \mu \mathrm{l}\right)$ & $1232.00 \pm 1.065$ & $1241.00 \pm 1.801$ & $1243.00 \pm 0.763$ & $1239.00 \pm 1.054$ \\
\hline SGOT (U/L) & $88.96 \pm 0.424$ & $89.10 \pm 0.427$ & $89.40 \pm 0.503$ & $89.65 \pm 0.356$ \\
\hline SGPT (U/L) & $32.53 \pm 0.630$ & $32.24 \pm 0.660$ & $31.32 \pm 0.550$ & $33.13 \pm 0.294$ \\
\hline
\end{tabular}

Values are expressed as mean \pm SEM of 6 rats in each group. $\mathrm{P}<0.05$ was considered significant. No significant difference was observed in any parameter.

tion is suitable for the development of prolonged drug release formulation..$^{28}$

\section{Particle size and Melting point determination}

The particle size of gum was in the range of 100-200 $\mu \mathrm{m}$. The calculated average diameter of the Gum Katira powder is found to be about $123 \mu \mathrm{m}$, which is within the desired range of $75-125 \mu \mathrm{m}$ for most of the gum powder particles used in various sustained release formulation. The natural products have a range of melting point rather than a definite melting point of pure products. During the melting process the transition of solid phase to liquid phase of gums is always accompanied by charring. Similar, charring characteristic of Gum Katira at $80-90^{\circ} \mathrm{C}$ confirms it as a novel excipient for sustained drug delivery system. ${ }^{29}$

\section{Moisture content determination}

Moisture content of gummy excipients used in formulations can influence the chemical and physical stability of active pharmaceutical ingredients and also the formulation. The moisture content of natural polysaccharide used as drug release excipients should be $\leq 15 \%$ in according to the pharmacopoeia and WHO guidelines. ${ }^{30}$ Moisture content of Gum Katira powder was found to be $13.21 \pm 0 . \%$ which is within the mentioned limits. So, in terms of moisture content Gum Katira can be successfully used in a sustained release formulation.

\section{Microbial Load Study}

The sample was analyzed for total aerobic microbial count and fungal count by pour plate method. Total aerobic count should be less than $1000 \mathrm{CFU} / \mathrm{g}$ and total fungal count should be less than $100 \mathrm{CFU} / \mathrm{g}$ to pass the microbial limit test. ${ }^{31}$ Microbial count study shows that total number of colonies for aerobic count is $210 \mathrm{CFU} / \mathrm{g}$ and total fungal count $93 \mathrm{CFU} / \mathrm{g}$ which is within the mentioned limits. Therefore the Gum Katira can be used for formulation development.

\section{Toxicity Study of Gum Katira}

Acute toxicity study was conducted on mice with the gum katira which revealed no behavioral changes and also no mortality was observed even at a dose level of $2.0 \mathrm{~g} / \mathrm{kg}$ body weight, after 24 hours of per-oral administration. Subacute toxicity study was conducted on rat whose haematological analysis (Table 1) after thirty days of oral administration showed no significant variance in the level of hemoglobin, RBC, WBC, neutrophil, eusinophil, monocyte, lymphocyte, SGOT, SGPT and platelets in treated animals as compared to that of the control group animals. Also, the histopathological studies (Figure 1) of treated animals revealed no significant tissue damage of the kidney and liver and were comparable to that of the control group. So, no abnormalities in histopathological studies were found. On the basis of the toxicity study conducted it can be concluded that the gum katira is safe to be used in the formulation.

\section{Percentage swelling of Gum}

Hydrophilic polymers undergo swelling at a rate proportional to the amount of polymer irrespective of the nature of the drug. Due to stress induced by ingresses water the polysaccharide matrix initially shows rapid swelling, with progressive increment in size along with entanglement of polymeric chain which forms a periphery gelatinous layer around the core through which diffusion of drug molecules takes place. ${ }^{32}$ Thickness of gelatinous layer determines the drug release from matrix. Drug diffusion also depends on the viscosity of the swollen region which in turn depends on the amount of polymer in the matrix. During the swelling characteristic study it was observed that initially both the formulations showed rapid swelling and at around 8-9 ${ }^{\text {th }}$ 


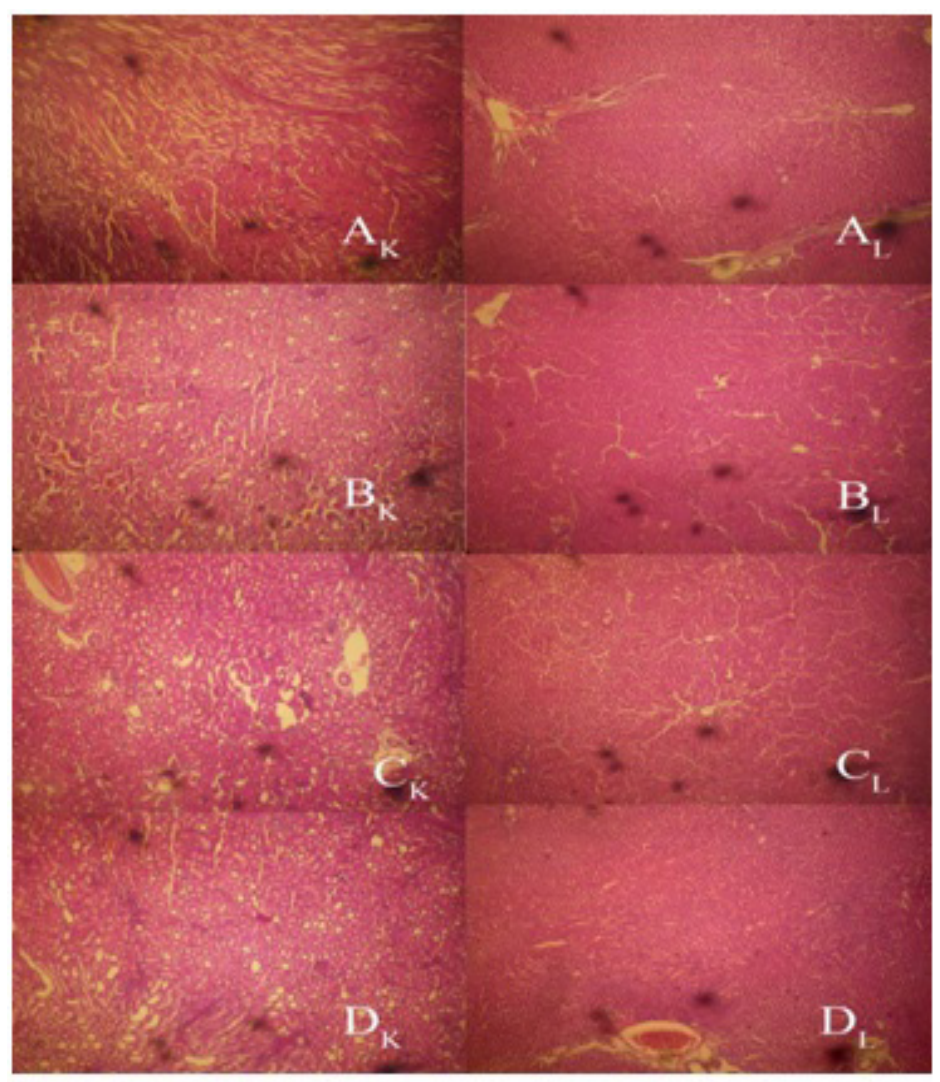

Figure:1 Histopathology of Kidney and Liver of rat after 30 days oral administration of Gum Katira (AK-Control Kidney, AL-Control Liver; BK-Treated $100 \mathrm{mg} / \mathrm{kg}$ Kidney, BL-Treated $100 \mathrm{mg} / \mathrm{kg}$ Liver; CK-treated $200 \mathrm{mg} / \mathrm{kg}$ Kidney, CL-Treated $200 \mathrm{mg} / \mathrm{kg}$ Liver and DKtreated $400 \mathrm{mg} / \mathrm{kg}$ Kidney, DL-treated $400 \mathrm{mg} / \mathrm{kg}$ Liver)

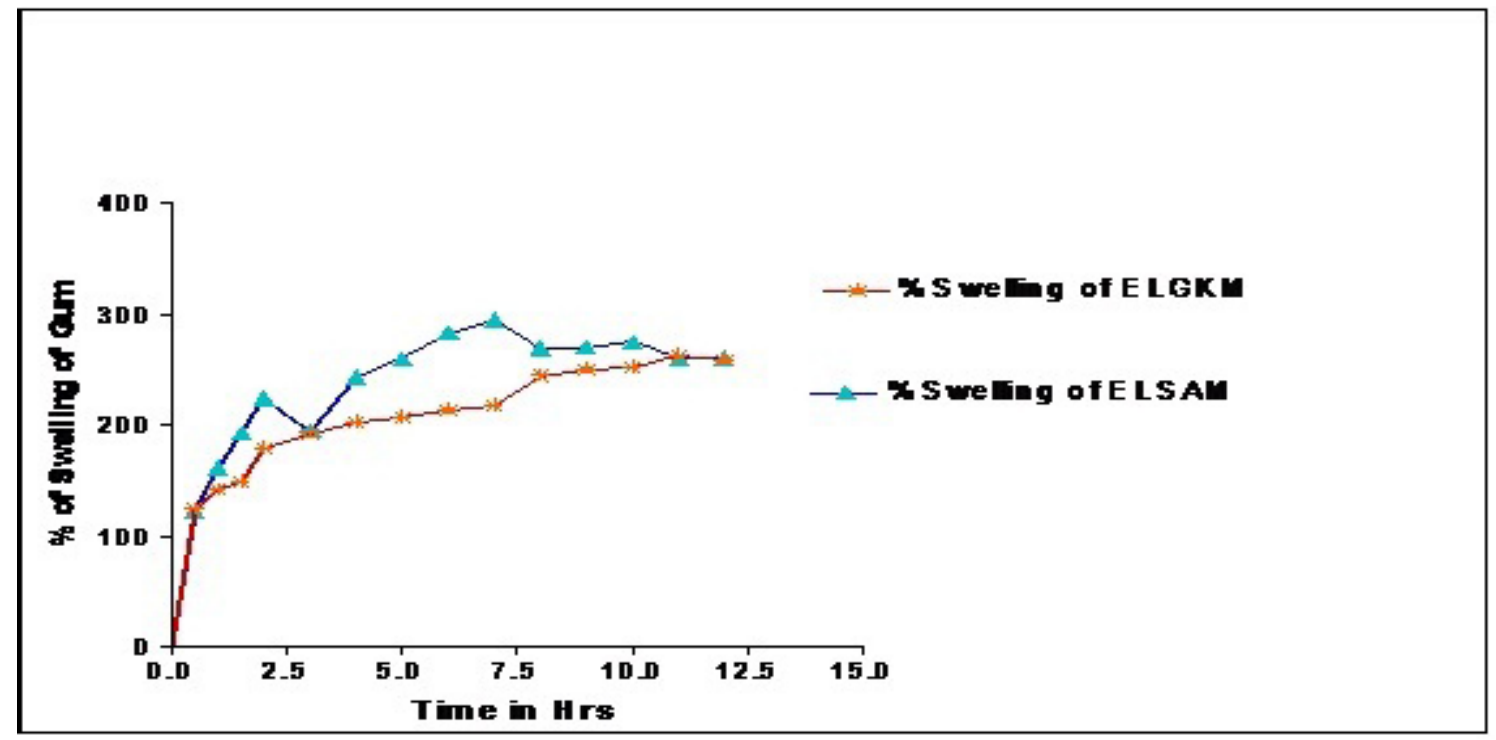

Figure 2: Comparison of \% of Swelling between ELGKM and ELSAM in SGF (pH-1.2) and SIF (pH-6.8)

hrs they attained maximum swelling after which there was a percentage decrease in swelling due to erosion of the axial layer, which promotes water penetration in the preceding layers. ${ }^{33}$ The swelling performance of $1 \%$ w/v (gummy) of ELGKM and ELSAM are shown in the (Figure 2). The maximum percentage of swelling of
Gum Katira was achieved at $11^{\text {th }}$ hrs but Sodium alginate at $7^{\text {th }}$ hr after which they start losing their integrity. ELGKM showed slow and continuous swelling up to $11 \mathrm{hrs}$ followed by decrease in swelling percentage which may be due to polymeric relaxation, whereas ELSAM showed faster swelling followed by immedi- 


\section{Table 2: Swelling rate of ELGKM and ELSAM in acidic} (pH-1.2) and buffer (pH-6.8) solution

\begin{tabular}{|c|c|c|}
\hline Formulation & $\begin{array}{c}\text { Rate of } \\
\text { swelling }\end{array}$ & $\begin{array}{c}\text { Correlation } \\
\text { Coefficient( }{ }^{2} \text { ) }\end{array}$ \\
\hline ELGKM (1\% Gum Katira) & 49.874 & 0.9728 \\
\hline ELSAM (1\% Sodium alginate) & 48.246 & 0.7379 \\
\hline
\end{tabular}

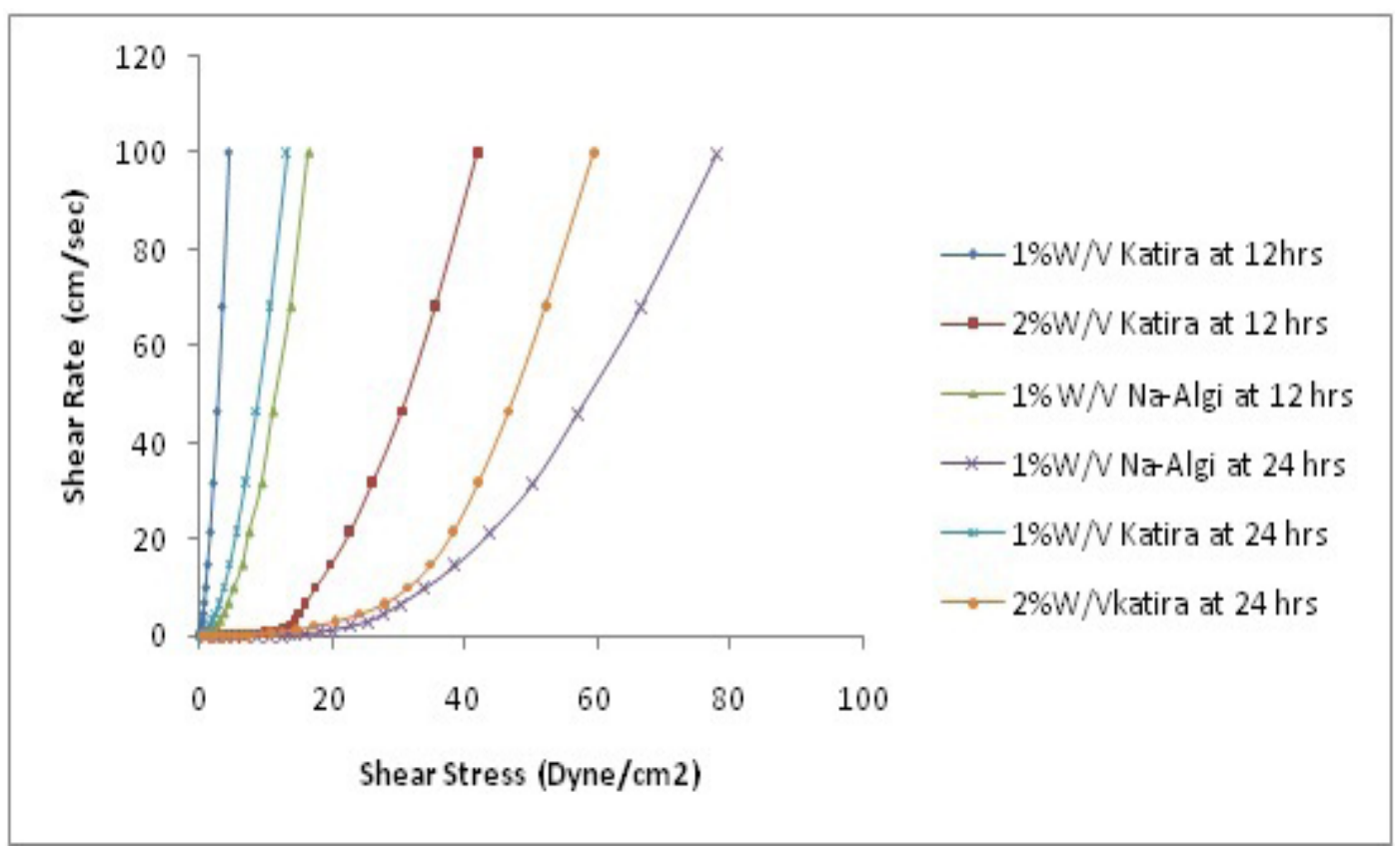

Figure 3: Rheogram of Gum Katira and Sodium Alginate solution of different concentration on different times

\begin{tabular}{|c|c|c|c|c|c|c|c|}
\hline Formulation Code & $\begin{array}{l}\text { Drug } \\
\text { (mg) }\end{array}$ & $\begin{array}{c}\text { Gum } \\
(\% \mathrm{w} / \mathrm{v})\end{array}$ & $\begin{array}{c}\text { Eudragit } \\
\text { RS } 100(\% \mathrm{w} / \mathrm{v})\end{array}$ & $\begin{array}{c}\text { Eudragit } \\
\text { RL } 100(\% \\
\text { w/v) }\end{array}$ & $\begin{array}{c}\text { Acryflow } \\
\text { (\% w/v) }\end{array}$ & $\begin{array}{c}\text { Span } 20 \\
(\mu \mathrm{l})\end{array}$ & $\begin{array}{c}\text { Tween } 80 \\
(\mu \mathrm{l})\end{array}$ \\
\hline$F_{A}$ (Katira) & 100 & 0.50 & 3.75 & 1.25 & 0.30 & 100 & 20 \\
\hline$F_{B}$ (Katira) & 100 & 1.00 & 3.75 & 1.25 & 0.30 & 100 & 20 \\
\hline$F_{c}$ (Katira) & 100 & 2.00 & 3.75 & 1.25 & 0.30 & 100 & 20 \\
\hline$F_{D}$ (Katira) & 100 & 3.00 & 3.75 & 1.25 & 0.30 & 100 & 20 \\
\hline$F_{E}$ (Alginate) & 100 & 1.00 & 3.75 & 1.25 & 0.30 & 100 & 20 \\
\hline$F_{F}$ (Blank) & 100 & 0.00 & 3.75 & 1.25 & 0.30 & 100 & 20 \\
\hline
\end{tabular}

$\% \mathrm{w} / \mathrm{v}=$ Amt. of ingredients $(\mathrm{mg})$ present in $100 \mathrm{ml}$ solvent

ately decrease in swelling as compared to ELGKM. It is also observed that percentage of swelling increases with increase in gum concentration up to a certain limit after which further increase in gum concentration decreases swelling due to inhibition of water penetration into the matrix. In the (Table 2), the slope of percentage swelling vs. time indicates that rate of swelling of ELGKM in the dissolution media ( $\mathrm{pH}-1.2$ acidic media and pH-6.8 phosphate buffer) is greater than ELSAM. So, it is expected that the drug release from ELGKM should be more prolonged than that of ELSAM.

\section{Rheological Study}

In pseudoplastic flow the consistency curve begins at the origin. As the shear stress increases progressively, shear rate also increases, but the curve is not linear. These types of curves are generally exhibited by Non-Newtonian system such as polymeric solution of sodium alginate. ${ }^{34}$ The rheogram of Gum Katira(1\% $\mathrm{w} / \mathrm{v}, 2 \% \mathrm{w} / \mathrm{v})$ and sodium alginate $(1 \% \mathrm{w} / \mathrm{v})$ solution at different time interval $\left(12^{\text {th }}\right.$ and $24^{\text {th }}$ hrs $)$ are graphically presented in (Figure 3). The rheograms of aqueous dispersion of both gums indicate pseudoplastic flow. But it 


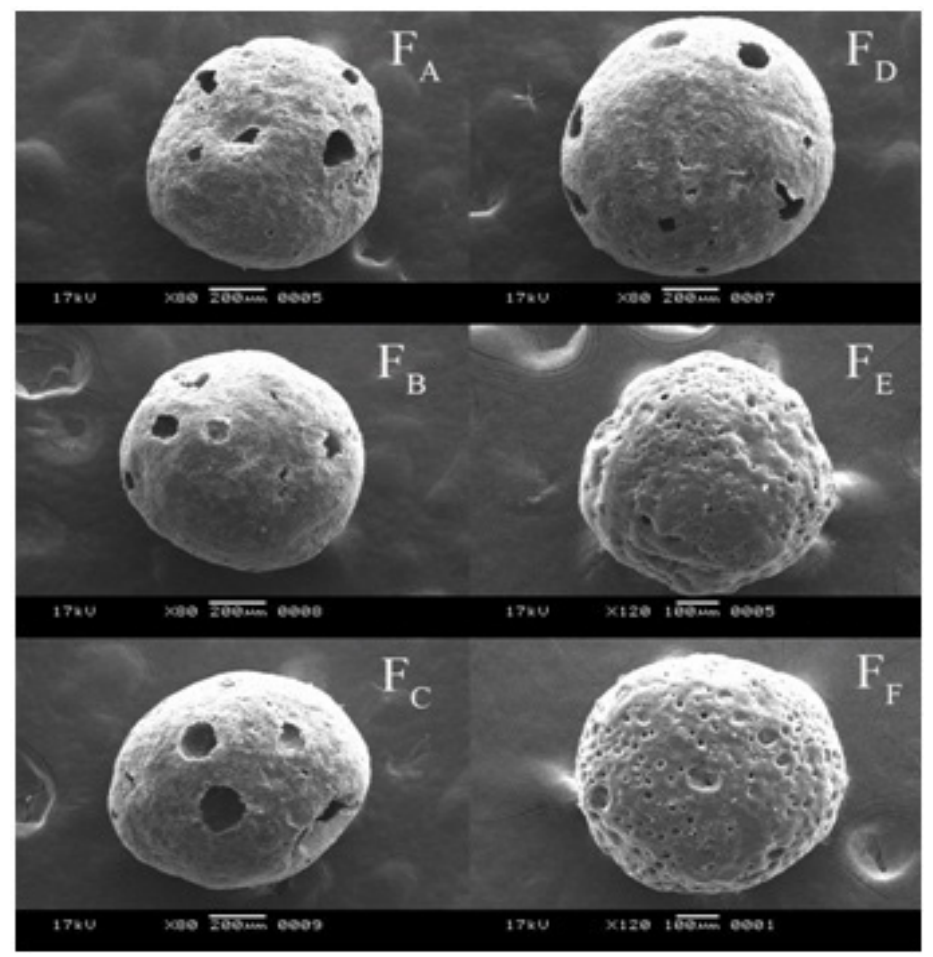

Figure 4: SEM of Etodolac loaded gum katira and sodium alginate Microsphere and Blank Microspheres. $F_{A}=\left[0.5 \% w / v\right.$ of Gum Katira], $F_{B}=[1.0 \%$ w/v of Gum Katira $], F_{C}=[2.0 \% \mathrm{w} / \mathrm{v}$ of Gum Katira $], F_{D}=[3.0 \% \mathrm{w} / \mathrm{v}$ of Gum Katira $], F_{E}=[1.0 \%$ w/v of sodium alginate $], F_{F}=[w$ without qum, Blank]

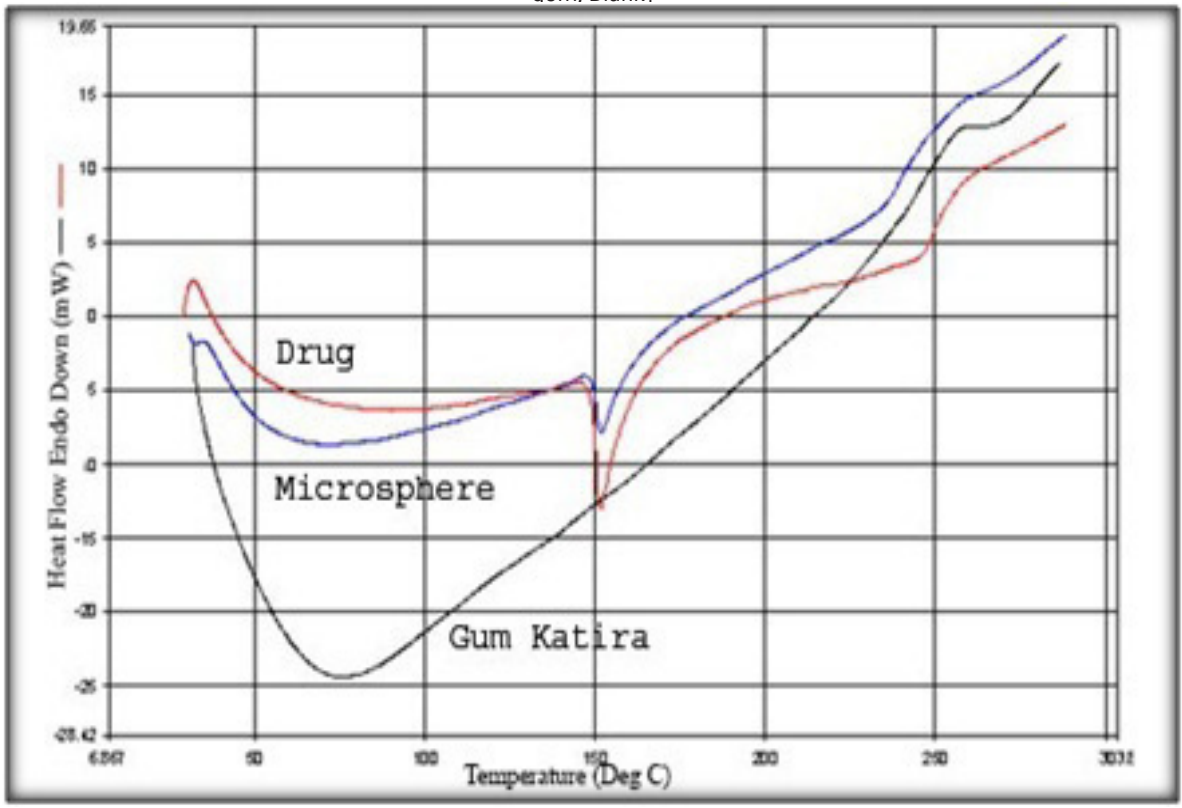

Figure 5: DSC of Gum Katira, Etodolac and Microsphere

was also seen that at lower concentration of Gum Katira the curve does not follow proper pseudoplastic flow which is due to very weak molecular interaction among the polymer molecules. In the study, the viscosity of gum solution decreases with increase in rate of shear and so no single value can be used to express its viscosity. The entire system is most satisfactory representation of Gum Katira as a pseudoplastic material.

\section{Characterization/ Evaluation of Microsphere Percentage of Yield and Encapsulation Efficiency}

The percentage yield and encapsulation efficiency of Etodolac were optimum in all formulations. Yet, due to variation of polymer type, stirring speed and polymer drug ratio some formulation were affected. Like with the increase in rate and duration of stirring the drug loading was seen decreasing. Also, with increase in amount 


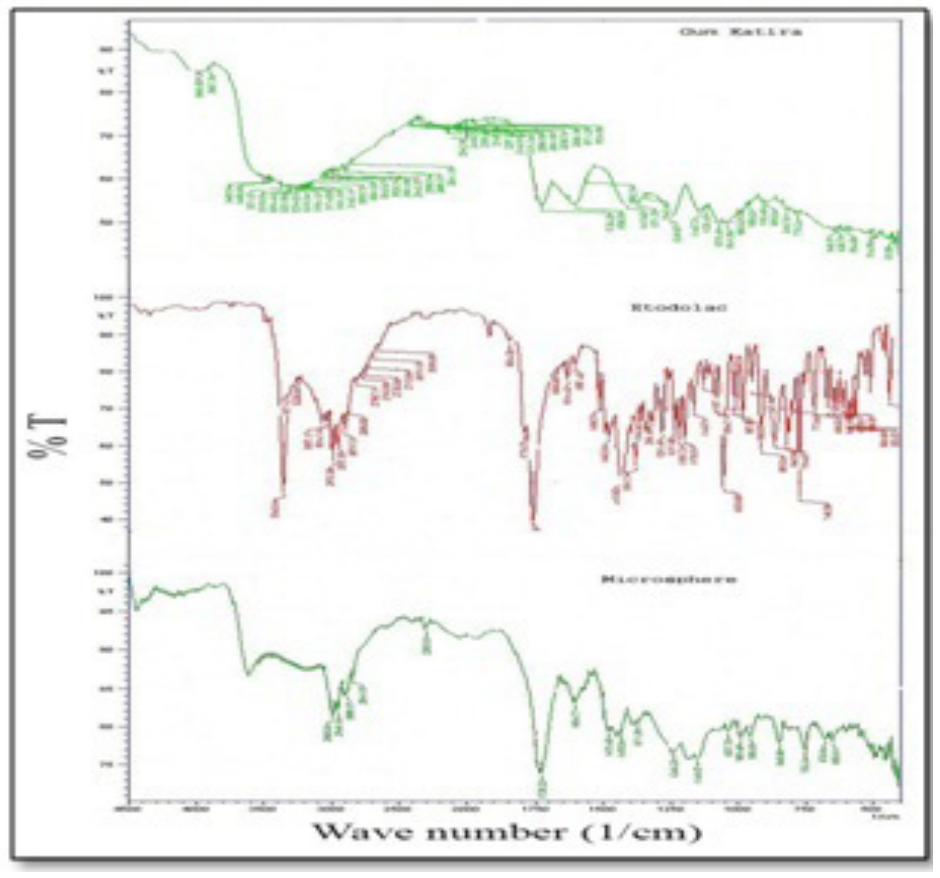

Figure 6: FTIR spectrum of Gum Katira, Drug Etodolac and Microsphere

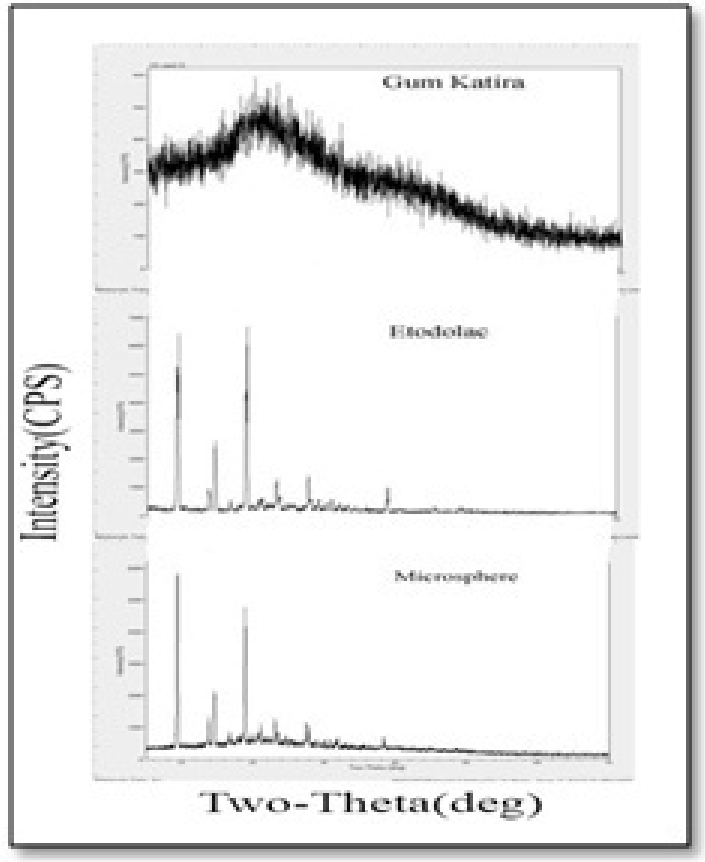

Figure 7: XRD study of Gum Katira, Drug Etodolac and Microsphere

of coating polymer, Eudragit the drug loading increases to some extent. But, the drug loading increases upto an optimum ratio (gum katira: Etodolac 1:2) of Gum Katira and Etodolac after which any increase in the ratio decreases the drug loading (Table 3).

\section{Scanning Electron Microscope}

The SEM is used to determine the particle size distribution, surface morphology, texture and also to examine the morphology of fracture or sectioned surface of the prepared microsphere. The absence of pore in the formulation is of major importance for the underlying drug release mechanisms because drug release through water filled cavities is much faster than though dense polymeric matrix network. SEM of ELGKM $\left(\mathrm{F}_{\mathrm{A}}, \mathrm{F}_{\mathrm{B}}\right.$, $\left.\mathrm{F}_{\mathrm{C}} \& \mathrm{~F}_{\mathrm{D}}\right), \operatorname{ELSAM}\left(\mathrm{F}_{\mathrm{E}}\right)$ and Blank microsphere $\left(\mathrm{F}_{\mathrm{F}}\right)$ are shown in the (Figure 4). All microspheres were spherical in shape; smooth surfaced and had minute pores on the surface. The surface of ELGKM was found to be 


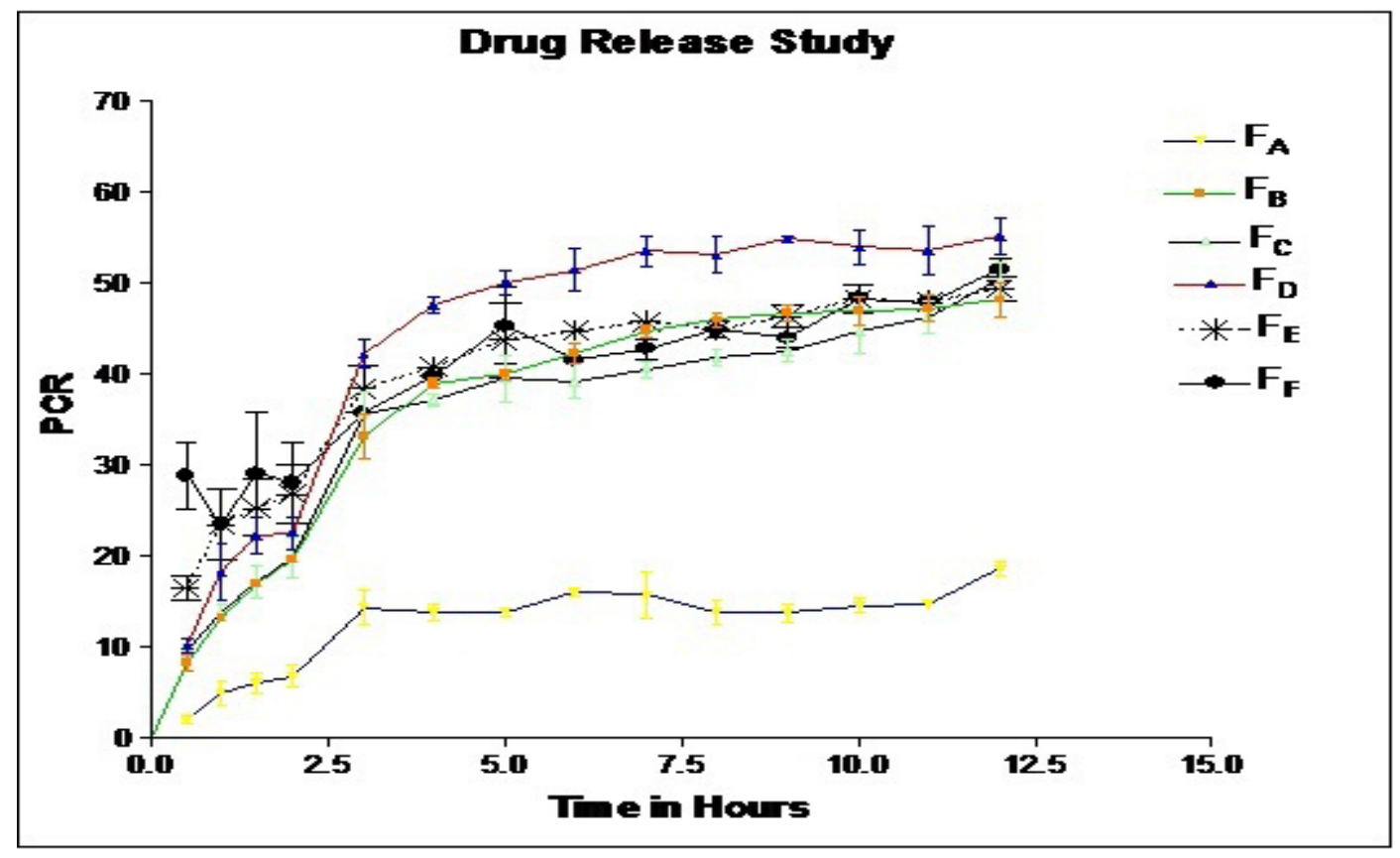

Figure 8: Drug release from ELGKM with different \% of Gum Katira, ELSAM and Blank Microsphere in SGF (pH-1.2) and SIF (6.8) in a continuous process

smooth bearing small pores whereas in case of ELSAM and Blank microsphere the surface was rough bearing larger pores. In the study, the formulations with Gum Katira bearing smooth surface showed slower rate and prolonged drug release as compared to the formulation without Gum Katira. ${ }^{35}$

\section{Differential Scanning Calorimetry}

DSC was performed to study the changing thermal behavior of the drug, polymer and gum during formulation. A sharp symmetric endothermic peak represents the melting point of the pure sample whereas a broad asymmetric curve in the DSC thermogram conveys about the presence of impurities in the sample. Generally, large endothermic and exothermic peak indicates the thermal decomposition of the sample. Also, the broad and large endothermic peak usually indicates the loss of water present in the compound. ${ }^{36}$ Amorphous compound gives a broad peak due to the gradual decomposition of exudates structure but a crystalline solid require a fixed amount of energy for decomposition and gives a sharp peak. In (Figure 5), a sharp endothermic peak at $15^{\circ} \mathrm{C}$ and broad endothermic peak at $50-90^{\circ} \mathrm{C}$ suggests the melting point of Etodolac and melting range of Gum Katira respectively. The thermogram of the microsphere showed little endothermic peak shift from $151.90^{\circ} \mathrm{C}$ to $152.12^{\circ} \mathrm{C}$ which is negligible. From the DSC conducted, it is clear that Gum Katira does not produce any thermal changes with the drugs and other ingredients used in microsphere formulations. So, both gum and Etodolac are compatible with each other as they are essentials for sustained drug delivery system.

\section{FTIR Study}

FTIR was conducted to study chemical interaction between the active ingredient, Etodolac and all the other excipients used in the formulation. The entire observed spectrum is given in (Figure 6) where the characteristic peaks of ELGKM was compared with that of the standard spectrum of Etodolac and no chemical interaction was identifiable in IR profile of ELGKM. Etodolac having ether form shows the C-O stretching vibration at $1033.85 \mathrm{~cm}^{-1}$. The other characteristic bands are shown at $1728.22 \mathrm{~cm}^{-1}$ for $\mathrm{C}=\mathrm{O}$ stretching vibration of the $\mathrm{COOH}$ group, at 2970.38 $\mathrm{cm}^{-1}$ for $\mathrm{N}-\mathrm{H}$ stretching vibration of secondary amine group and at $748.38 \mathrm{~cm}^{-1}$ for $\mathrm{C}-\mathrm{H}$ stretching vibration of aromatic group. ${ }^{37}$ So, FTIR study suggests that there is no appearance of new peak and disappearance of existing peak which denotes an absence of interaction between the drug and excipients used in microsphere formulations.

\section{XRD study}

According to the powder crystalline theory the crystalline substance have a well defined structure. Atoms, ions and molecules are arranged in a three dimensional lattice which results in tight packing of components so well defined edges and faces diffract X- ray in a regular pattern. Amorphous solids have curved and irregular surface so does not give well resolved dif- 


\begin{tabular}{|c|c|c|c|c|c|c|c|c|c|c|c|}
\hline \multirow{2}{*}{$\begin{array}{c}\text { Formulation } \\
\text { Code }\end{array}$} & \multicolumn{2}{|c|}{ Zero Order } & \multicolumn{2}{|c|}{ First Order } & \multicolumn{2}{|c|}{ Higuchi } & \multicolumn{3}{|c|}{ Korsmeyers Peppas } & \multicolumn{2}{|c|}{ Hixon Crowell } \\
\hline & $\mathrm{K}_{0}$ & $\mathbf{R}_{0}^{2}$ & $\mathrm{~K}_{1}$ & $\mathbf{R}_{1}^{2}$ & $K_{h}$ & $\mathbf{R}_{h}^{2}$ & $\mathbf{n}$ & $K_{k p}$ & $\mathbf{R}_{\mathrm{kp}}^{2}$ & $\mathrm{~K}_{\mathrm{hc}}$ & $\mathbf{R}_{\mathrm{hc}}^{2}$ \\
\hline $\mathrm{F}_{\mathrm{A}}$ & 1.029 & 0.6513 & -0.008 & 0.6761 & 4.814 & 0.7688 & 1.181 & 0.661 & 0.8557 & 0.080 & 0.6004 \\
\hline$F_{B}$ & 3.311 & 0.8032 & -0.006 & 0.8015 & 15.17 & 0.9116 & 3.012 & 0.988 & 0.9939 & 0.120 & 0.7326 \\
\hline$F_{c}$ & 3.078 & 0.8168 & -0.019 & 0.8157 & 13.98 & 0.91 & 1.035 & 1.171 & 0.9403 & 0.111 & 0.7457 \\
\hline$F_{D}$ & 3.570 & 0.7319 & -0.022 & 0.6697 & 16.61 & 0.8566 & 1.057 & 1.253 & 0.9151 & 0.1162 & 0.6756 \\
\hline$F_{E}$ & 2.501 & 0.7896 & -0.020 & 0.9183 & 11.50 & 0.9013 & 0.684 & 1.357 & 0.9486 & 0.0798 & 0.7387 \\
\hline$F_{F}$ & 2.111 & 0.8598 & -0.015 & 0.8415 & 9.306 & 0.9021 & 0.463 & 1.441 & 0.8564 & 0.063 & 0.8287 \\
\hline
\end{tabular}

$\mathrm{K}^{\prime}$ value (Rate of release), $\mathrm{n}$ value (release exponent) and Correlation coefficient ' $\mathrm{R}^{2 \prime}$ according to different kinetic equation for ELGKM, ELSAM and Blank microsphere respectively. All the data (K) were found to be significant at the level of $\mathrm{P}<0.0001$ assessed by One-way ANOVA using graph pad prism 5

\begin{tabular}{|c|c|c|}
\hline \multicolumn{2}{|c|}{ Table 5: Interpretation of Diffusional Release Mechanism from Poly- } \\
meric films
\end{tabular}

fractrogram. ${ }^{38}$ The powdered X ray diffraction of Gum Katira, Etodolac and formulation are shown in the (Figure 7) where, the diffraction pattern of pure Etodolac and Etodolac loaded Gum Katira microsphere shows crystalline peak but Gum Katira alone gives amorphous peak. The result demonstrates that the crystalline peak of drug and formulation are almost similar but peak intensity diminishes in the formulation diffractrogram due to dilution of the drug with gum and polymer. So, the conducted XRD experiment also suggests that Etodolac is compatible with Gum Katira. Therefore the Gum Katira can be used as a novel matrix forming excipient for the sustained drug delivery system.

\section{Dissolution Profile and Release rate kinetics}

The mechanism of drug release from the microspheric formulation is biphasic in nature. Dissolution was carried out and it was observed that the drug release from the microspheres in acidic media $\mathrm{pH}-1.2$ was too low in comparison to USP phosphate buffer media pH-6.8. Where, in buffer media at pH-6.8 the drug release gradually increased and followed a steady state (Figure 8). Such release profile of the drug is observed mainly due to variation in solubility of drug and percentage swelling of gum at different $\mathrm{pH}$. The drug is less soluble at pH-1.2 and highly soluble at pH-6.8 which accounts for higher rate of drug release in phosphate buffer at $\mathrm{pH}-6.8$ than in acidic media at $\mathrm{pH}-1.2$. Also initial slow drug release reflects the time consuming processes of diffusion through the polymer wall, as well as the formation of pores and channels within the microspheres. Therefore, at $\mathrm{pH}-6.8$ where the percentage of swelling of gum is high as observed in (Figure 2) there is an increase in pore size which accounts for better and increased drug release. he collected drug release data from the dissolution test were evaluated using number of kinetic models like Zero order ${ }^{39}$ release kinetics Eq. 1., First Order ${ }^{40}$ Eq. 2, Higuchi's square root of time equation ${ }^{41}$ Eq. 3, Korsemeyer and Peppas equation ${ }^{42}$ Eq. 4, and Hixon-Crowells cube root of time equation ${ }^{43}$ Eq. 5.

$\mathrm{C}=\mathrm{K}_{0} \mathrm{t}$

Where, $\mathrm{K}_{0}$ is zero order rate constant expressed as concentration/ time and $\mathrm{t}$ is the time.

$\log C=\log _{0}-\mathrm{K}_{1} \mathrm{t} / 2.303(2)$

Where, $\mathrm{C}_{0}$ is the initial concentration of drug and $\mathrm{K}_{1}$ is first order constant.

$\mathrm{Q}=\mathrm{K}_{\mathrm{h}} \mathrm{t}$

Where, $\mathrm{K}_{\mathrm{h}}$ is the constant reflecting the design variables of the system.

$\mathrm{M}_{\mathrm{t}} / \mathrm{M}_{\infty}=\mathrm{K}_{\mathrm{kp}} \mathrm{t}^{\mathrm{n}}$

Where, $\mathrm{Mt} / \mathrm{M}_{\infty}$ is the fraction of drug release, $\mathrm{K}_{\mathrm{kp}}$ is the release rate constant, $\mathrm{n}$ is the diffusional release exponent indicative of the drug release mechanism and $t$ is the dissolution time.

$\mathrm{Q}_{0}{ }^{1 / 3}-\mathrm{Q}_{\mathrm{t}}{ }^{1 / 3}=\mathrm{K}_{\mathrm{hc}} \mathrm{t}$

Where, $Q_{t}$ is the amount of the drug released in time $t$, $\mathrm{Q}_{0}$ is the initial amount of drug in the formulation and $\mathrm{K}_{\mathrm{hc}}$ is the rate constant for Hixson- Crowell rate equation. The best fitted model was analyzed by comparing the correlation coefficient value of different mathematical models in (Table 4). From the recorded data the correlation coefficient value of ELGKM $\left(r^{2}=0.9939\right)$ is found to be higher than that of ELSAM $\left(\mathrm{r}^{2}=0.9486\right)$ in equal percentage of gum. Thus, Korsmeyers Peppas model was the 
best satisfactory mathematical model for ELGKM (1\% w/v Gum Katira). Based on Korsmeyers Peppas model, the magnitude of release exponent " $\mathrm{n}$ " correspond to the release mechanism supercase II transport or anamolous transport, which can be concluded on comparing the value of $n=3.012$ which is greater than the value 0.89 (Table 5). Similarly, for ELSAM the " $n$ " value i.e. $n=0.684$ is within the range of 0.45 to 0.89 thus it follows non-fickian transport release mechanism. In this regard, the drug release from microspheric formulation of Gum Katira followed the supercase II transport mechanism whereas formulation with sodium alginate and Blank microsphere followed non fickian transport mechanisms.

\section{CONCLUSION}

The evaluation of the different physiochemical parameters of Gum Katira reveals its potential to be a superior matrix for sustained release. The stability in terms of rheology and safety profile showed the acceptability of formulations composing of Gum Katira. The microsphere prepared by double emulsion solvent evaporation method delivers the drug in a regular fashion for an extended period of time. Consequently, it can be concluded that the gum exudates of Cochlospermum religiosum, when incorpo- rated with etodolac may be potential pharmaceutical formulation for the safe management of pain therapy.

\section{ACKNOWLEDGEMENT}

The authors would like to thank University Grants Commission (UGC), New Delhi, India for the financial purport. The authors also greatly acknowledge Mr. Soumen Mukhopadhyay, Deputy Drug Controller of India, East Zone for extending his support in this research.

\section{ABBREVIATION}

$\begin{array}{ll}\text { ANOVA } & : \text { Analysis of Variance } \\ \text { CFU } & : \text { Colony forming unit } \\ \text { ELGKM } & : \text { Etodolac loaded gum katira micro } \\ & \text { sphere } \\ \text { ELSAM } & : \text { Etodolac loaded sodium alginate } \\ & \text { microsphere } \\ \text { OECD } & : \text { Organization for economic coopera } \\ & \text { tion and development } \\ \text { SGOT } & : \text { Serum glutamic oxaloacetic transami } \\ & \text { nase } \\ \text { SGPT } & : \text { Serum glutamic pyruvic transaminase }\end{array}$

\section{SUMMARY}

- Gum Katira is a natural gum obtained from the plant Cochlospermum religiosum (Family Cochlospermaceae).

- On the basis of its physiochemical characters, Gum Katira is a good drug release retarding agent. and thus it acts as an excipint in the novel drug delivery system.

\section{About Authors}

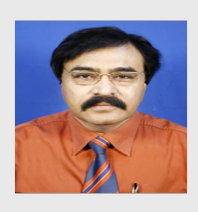

Dr. T.K. Chatterjee: An Ex-UGC (Govt. of India) Research Scientist and presently a Faculty member of the Department of Pharmaceutical Technology of Jadavpur University, Kolkata, has been actively engaged in Pharmacology \& Toxicology research and teaching for the last 3 decades.

He has been resourceful contributor of more than 108 research papers in journals of National and International repute, and he has to his trust worthiness as a distinguished author of ten books on pharmacology that attracted widespread recognition from various organizations of Pharmaceutical, Medical and allied sciences. International conferences in different countries like Sweden, Belgium, Germany and U.K. have also been enriched by his resourceful papers, a number of times. He was facilitated by different organization awarding him with prestigious awards like Ram Mohan Puraskar, Aadi Samman, NIMA Award, Nagarjun Puraskar for his contribution in Pharmaceutical Sciences.

With the discovery of a new antibiotic MT-81(Patent No. 156916), Dr. Chatterjee's research work stands in high esteem embracing indepth study on the subject, and thus adding a new plume into his ever increasing contribution in the fields of Medical healthcare.

\section{REFERENCES}

1. Bharaniraja B, Kumar KJ, Prasad CM, Sen AK. Different approaches of Katira gum formulations for colon targeting. Int J Biol Macromol. 2011; 49(3): 305-10.

2. Keerthi TS, Kumar SKS. Formulation and evaluation of microspheres of losartan potassium using biodegradable natural polymers. Int bull drug res. 2012; 1(2): 120-31.
3. Xi MM, Zhang SQ, Wang XY, Fang KQ, Gu Y. Study on the characteristics of pectin-ketoprofen for colon targeting in rats. Int J Pharm. 2005; 298(1): 91-7.

4. Chourasia MK, Jain SK. Pharmaceutical approaches to colon targeted drug delivery systems. J Pharm Sci. 2003; 6(1): 33-66.

5. Sinha VR, Kumaria R. Microbially triggered drug delivery to the colon. Eur J Pharm Sci. 2003; 18(1): 3-18. 
6. Follonier N, Doelkar E. Biopharmaceutical Comparison of Oral Multiple-unit and Single-unit Sustained Release Dosage Forms. STP Pharma Sciences 1992; 2(2): 141-58.

7. Varde NK, Pack DW. Microspheres for Controlled Release Drug Delivery. Expert Opin Biol Ther. 2004; 4(1): 35-51.

8. Sujja AJ, Munday DL, Khan KA. Development and evaluation of a multipleunit oral sustained release dosage form for $\mathrm{S}(+)$-ibuprofen: preparation and release kinetics. Int J Pharm. 1999; 193(1): 73-84.

9. Emeje M, Nwabunike P, Isimi C, Fortunak J, Mitchell JW, Byrn S, et al. Isolation, characterization and formulation properties of a new plant gum obtained from Cissus refescence. Int J Green Pharm. 2009; 3(1): 16-23.

10. Halsas M, Hietala J, Veski $P$, Jürjenson H, Marvola M. Morning versus evening dosing of ibuprofen using conventional and time controlled release formulation. Int J Pharm. 1999; 189(2): 179-85.

11. Chourasia MK, Jain SK. Polysaccharides for colon targeted drug delivery. Drug Deliv. 2004; 11(2): 129-48.

12. Bharaniraja B, Kumar KJ, Prasad CM, Sen AK. Modified Katira Gum for Colon Targeted Drug Delivery. J Appl Polym Sci. 2011; 119(5): 2644-51.

13. Ojha AK, Maiti D, Chandra K, Mondal S, Das D, Roy SK, et al. Structural assignment of a heteropolysaccharide isolated from the gum of Ochlospermum religiosum (Katira gum). Carbohydr Res. 2008; 343(7): 1222-31.

14. Wealth of India. Vol. 2, CSIR, New Delhi, India; 1962.

15. Sharma VK, Mazumdar B. Feasibility and characterization of gummy exudate of Cochlospermum religiosum as pharmaceutical excipient. Ind Crops Prod. 2013; 50(1): 776- 86.

16. Veys EM. Clinical performance of etodolac in patients with osteoarthiritis and rheumatoid arthiritis. Eur J Rheumatol Inflamm. 1994; 14(1): 23-7.

17. Robinson RJ, Wai-Yip Lee T. Controlled -release Drug-Delivery Systems. In: Gennaro AR, Hanson RG (Eds.). Remington: The Science and Practice of Pharmacy. Lippincott Williams \& Wilkins, $20^{\text {th }}$ ed. Philadephia; 2000. 907-10.

18. John JM, Deborah MS, Richard JD. Sustained release Etodolac. US patent, US; 1990. 4966768.

19. Pal T, Paul S, Sa B. Polymethylmethacrylate Coated Alginate Matrix Microcapsules for Controlled Release of Diclofenac Sodium. Pharmacol Pharma. 2011; 2(02): 56-66.

20. Pandey VP, Manavalan R, Rajan S, Ganesh KS. Formulation and release characteristics of sustained release diltiazem hydrochloride tablet. Indian $\mathrm{J}$ Pharm Sci. 2003; 65(1): 44-8.

21. Sahoo SK, Mallick AA, Barik BB. Formulation and in vitro evaluation of Eudragit microspheres of stavudine. Trop J Pharm Res. 2005; 4(1): 369-75.

22. Eudragit RS, Eudragit RL. data sheets R^hm Pharma GmbH, Darmstadt; 1991.

23. Pignatello R, Bucolo C, Ferrara P, Maltese A, Puleo A, Puglisi G. Eudragit RS. 100 nanosuspensions for the ophthalmic controlled delivery of ibuprofen. Eur J Pharm Sci. 2002; 16(1-2): 53-61.

24. Haznedar S, Dortun B. Preparation and in vitro evaluation of Eudragit microspheres containing acetazolamide. Int J Pharm. 2004; 269(1): 131-40.

25. Joshi AS, Patil CC, Shiralashetti SS, Kalyane NV. Design, characterization and evaluation of Eudragit microspheres containing glipizide. Drug Discov. Today 2013; 5(3): 229-34.
26. Arun R, Sathish Y, Sravanthi VVNSS, Krishna VK, Theja I. Design, hydrolysis and pharmacological evaluation of novel polymeric pro-drugs of Etodolac. Der. Pharmacia. Lett 2009; 1(2): 9-17.

27. Leslie GH, Gerald LR. Oral formulations of $S(+)$ Etodolac. US patent, US: 1999. 5958445.

28. Shriram RS, Dhanorkar YD, Pahuja V, Kulkarni GT. Characterization of selected hydrogel polysaccharide hydrogels as pharmaceutical excipients. J Chronother Drug Delivery 2012; 3(2): 41-54.

29. Meka VS, Nali SR, Songa AS, Kolapalli VR. Characterization and in vitro drug release studies of a natural polysaccharide terminalia catappa gum (Badamgum). AAPS Pharm Sci Tech. 2012; 13(4): 1451-64.

30. World Health Organization. Quality control methods for medicinal plant materials. Geneva: WHO; 1998. p. 35.

31. Indian Pharmacopeia. Ministry of Health and family Welfare, Govt of India. $4^{\text {th }}$ edition. Controller of Publication, New delhi; 1996.

32. Singh R, Maity S, Sa B. Effect of ionic crosslink on the release of metronidazole from partially carboxymethylated guar gum tablet. Carbohydr Polym. 2014; 106(1): 414-21.

33. Jian H, Zhu L, Zhang W, Sun D, Jiang J. Galactomannan (from Gleditsia sinensis Lam.) and xanthan gum matrix tablets for controlled delivery of theophylline: In vitro drug release and swelling behavior. Carbohydr Polym. 2012; 87(3): 2176-82.

34. Subrahmanyam CVS. Text Book of Physical Pharmaceutics. $10^{\text {th }}$ ed, chapter 7, Vallabh Prakashan, Delhi; 2009. Pp. 244-8.

35. Hombreiro-Pérez M, Siepmann J, Zinutti C, Lamprecht A, Ubrich N, Hoffman $\mathrm{M}$, et al. Non-degradable microparticles containing a hydrophilic and/or a lipophilic drug: preparation, characterization and drug release modeling. Non-degradable microparticles containing a hydrophilic and/or a lipophilic drug: preparation, characterization and drug release modeling. J Control Release. 2003; 88(3): 413-28.

36. Beckett AH, Stenlake JB. Practical Pharmaceutical Chemistry. In: Solole EG (ed) Analysis of drugs and excipients in the solid state, $4^{\text {th }}$ ed. Part Two; CBS Publishers and Distributors, New Delhi; 2004. Pp. 52-84.

37. Barakat NS. Etodolac-liquid-filled dispersion into hard gelatin capsules: an approach to improve dissolution and stability of Etodolac formulation. Drug Dev Ind Pharm. 2006; 32(7): 865-76.

38. Averill B, Eldredge P. General chemistry: principles, patterns, and applications. elSBN. 2011; 1(12): 978-1-4533-3122-4.

39. Narashimhan B, Mallapragada SK, Peppas NA. Release kinetics, data interpretation. Encyclopedia of Controlled Drug Delivery. John Wiley and Sons, Inc, New York; 1999. p. 921.

40. Bourne DW. Pharmacokinetics. in: Banker GS, Rhodes CT (Eds) Modern pharmaceutics. $4^{\text {th }}$ edn. Marcel Dekker Inc, New York; 2002. Pp. 67-92.

41. Higuchi T. Rate of release of medicaments from ointment bases containing drugs in suspension. J Pharm Sci. 1961; 50(10): 874-5.

42. Korsmeyer RW, Gurny R, Doelker E, Buri P, Peppas NA. Mechanisms of potassium chloride release from compressed, hydrophilic, polymeric matrices: Effect of entrapped air. J Pharm Sci. 1983; 72(10): 1189-91.

43. Hixson AW, Crowell JH. Dependence of reaction velocity upon surface and agitation. Ind. Eng. Chem. 1931; 23(8): 923-31. 